\title{
Hormone replacement therapy and mortality in 52- to 70-year-old women: the Kuopio Osteoporosis Risk Factor and Prevention Study
}

\author{
Kati Pentti $^{1}$, Risto Honkanen ${ }^{2}$, Marjo T Tuppurainen ${ }^{1,2}$, Lorenzo Sandini ${ }^{2}$, Heikki Kröger ${ }^{2,3}$ \\ and Seppo Saarikoski ${ }^{1}$ \\ ${ }^{1}$ Department of Obstetrics and Gynecology, ${ }^{2}$ Bone and Cartilage Research Unit and ${ }^{3}$ Department of Surgery, Kuopio University Hospital, \\ FIN-70211, Kuopio, Finland
}

(Correspondence should be addressed to K Pentti; Email: kati.pentti@fimnet.fi)

\begin{abstract}
Objectives: To analyze prospectively the association between hormone replacement therapy (HRT) and mortality in women before old age.

Design and methods: A group of 11667 women (91\% of the age cohort of the area) aged 52-62 years from the population-based Kuopio Osteoporosis Risk Factor and Prevention Study were followed for 7 years in 1994-2001. Information about HRT use and health events was obtained from two repeated questionnaires in 1989 and 1994. Information about deaths and causes of death from the follow-up period was obtained from the Statistics Finland. Cox's proportional-hazards models were used to calculate risk of death related to the use of HRT.

Results: At the start of follow-up, 2203 women had used HRT $>5$ years, 3945 women $\leq 5$ years and 5519 women had never used it. During the follow-up, 361 deaths occurred. Compared with nonusers of HRT, the adjusted hazard ratio (HR) of death from any cause was 1.05 (95\% confidence interval (CI) $0.80-1.36)$ in women who used HRT $\leq 5$ years and 1.06 (95\% CI $0.78-1.46)$ in women who used HRT $>5$ years. The adjusted HR for coronary heart disease (CHD) mortality in women who used HRT $\leq 5$ years was 0.79 (95\% CI $0.36-1.73)$, and in women who used HRT $>5$ years, 2.16 (95\% CI $0.93-4.98)$. For breast cancer mortality the adjusted HR for $\leq 5$ years of HRT use was 0.96 (95\% CI $0.32-2.82)$ and 2.62 (95\% CI $0.98-7.00)$ for $>5$ years of HRT use.

Conclusions: History of HRT use does not affect overall or CHD mortality in women. More than 5 years of HRT use may increase the risk of breast cancer mortality.

European Journal of Endocrinology 154 101-107
\end{abstract}

\section{Introduction}

Before the Women's Health Initiative (WHI) (1-5), Heart and Estrogen/Progestin Replacement Study (6) and the Million Women (7) reports, estrogen use was considered to be associated with longer survival (8, 9). Hormone replacement therapy (HRT) use was seen to be associated with many beneficial effects, including a decreased risk of osteoporosis $(10,11)$ and fractures $(1,12)$ and cardiovascular disease $(8,9,13)$, but also with a slight increase in the risk of breast cancer $(7$, 10). On the other hand, Bush et al. (14) concluded in their review that estrogen and combined hormone therapy do not increase the risk of breast cancer. Earlier it had also been shown that unopposed estrogen use is associated with risk of endometrial cancer $(4,13)$. Recent randomized trials have shown a different picture of the effects of HRT use from earlier observational studies. The WHI study group reported that the risks of HRT use outweigh the benefits (1-5).
The observational Million Women Study reported that current use of HRT was associated with an increased risk of incident and fatal breast cancer. The effect was substantially greater for estrogen-progestagen combinations than for other types of HRT (7).

Because findings from these previous studies have been conflicting, and information concerning HRT and mortality is also still limited, it is important to obtain more information about the long-term systemic use of HRT and its possible benefits, such as prevention of coronary heart disease (CHD) and dementia, and, on the other hand, about its risks with respect to breast and uterine cancer (15). We need also information concerning the effects of HRT on mortality of women of different age cohorts. In this 7 year follow-up of the population-based Kuopio Osteoporosis Risk Factor and Prevention (OSTPRE) Study cohort, we examined the association between HRT history and overall mortality, CHD and breast cancer mortality in women aged $52-70$ years. 


\section{Subjects and methods}

\section{Study population}

This study is a part of the OSTPRE population-based prospective cohort study. The target population consisted primarily of the 14220 women resident in Kuopio Province and born in 1932-1941 (aged 4757 years in 1989). Names, addresses and social security numbers of these women were obtained from the National Population Register of Finland. The postal inquiry was sent to 14121 women (of the entire cohort of 14220 women) in May 1989. In all, 13100 women $(92.8 \%)$ responded. The follow-up inquiry was sent to women alive in May 1994. A total of 11798 women responded to both inquiries. Women whose HRT use could not be clarified were excluded $(n=131)$. Women who had reported breast cancer in 1989 or 1994 were included in the multivariate analysis. The final study population consisted of 11667 women, and the postmenopausal subgroup of 9354 women. A woman was regarded as postmenopausal if $\geq 12$ months had elapsed since her last natural menstruation or if she had undergone bilateral oophorectomy with or without hysterectomy and if the time since menopause and HRT use could be clarified in May 1994. Women whose menopause could not be defined due to hysterectomy $(n=1146$ of 11667$)$ were excluded from the postmenopausal subgroup. A total of 839 women were premenopausal (mean age 54.1 years) in May 1994. Women whose time since menopause could not be defined due to incomplete data $(n=328)$ were also excluded from the postmenopausal subgroup. For the multivariates analysis the entire study population consisted of 10956 women and the postmenopausal subgroup consisted of 8865 women. This study was approved by the local ethics committee in 1986, 1994 and 1997.

\section{Deaths}

Mortality data from the follow-up period (1 June 1994 until 14 May 2001) were obtained from the National Cause of Death Register, Statistics Finland. This national death register contains information on all deaths in the country from death certificates filled in by the physicians who take care of the patients before death. The death certificate follows the international format for death certifications issued by the WHO. The death certificate data are compared with the Central Population Register by means of the person identification code of the deceased. This ensures 100\% coverage. In Finland a death certificate issued by the physician is obtained for almost every deceased (16). Therefore possible bias due to incomplete or inaccurate mortality data is small.

The statistical underlying cause of death is coded from the causes of death on the death certificate issued by the physician with the help of statistical rules of the WHO. The causes of death are classified according to the revision of the International Classification of Diseases that was valid in Finland at the time of death (16). The Finnish National Registry mortality statistics have been shown to be accurate (17).

A total of 361 deaths were included in the analysis. The causes of death were coded according to the International Classification of Diseases, by use of ICD-9 and ICD-10 codes. First we assessed the association between HRT use and total mortality. Then we examined this association for two subgroups of causes of death: CHD (ICD-9 codes 4100-4149 and ICD-10 codes I200I259) and breast cancer (ICD-9 codes 1740-1749 and ICD-10 codes C500-C509).

\section{HRT}

In 1989, the lifetime use of HRT in years and the indication for HRT was recorded. In 1994 HRT form (gel, patch or tablet) and duration of use in months were asked for separately for each year from 1 June 1989 to 1994. Current medication prescribed by a doctor was also asked for in both inquiries. Women were asked to specify the names of medications, duration (in years) of medicine treatment and the names of diseases they were taking medications for. We defined HRT use as use of preparations having systemic estrogenic properties, and classified it as follows: no use of HRT, 0.05-5 years of HRT use and >5 years of HRT use. Inconsistent or missing HRT information was clarified by telephone interview or by further postal inquiry.

\section{Other variables}

The 1989 and 1994 inquiries included questions about gynecological history (parity, last menstruation and menopause symptoms) and surgery, use of female hormones (including oral contraceptives and HRT) in years and the reason for their use, height, weight, smoking, chronic health disorders diagnosed by a physician (with >100 different items, for example cancers, hypertension and coronary disease) and current use of prescribed drugs. Body mass index (BMI) was calculated as the ratio of weight in kilograms to height in meters squared.

\section{Statistical analysis}

The statistical analyses were performed with the Statistical Package for Social Sciences (SPSS, Inc., Tokyo, Japan) program. The chi-square test and one-way ANOVA were used to compare differences among groups. Cox's proportional-hazards models were used to study the association of HRT use with mortality from different causes after adjustment for 6-11 covariates. Specifically, the covariates were age, parity, BMI, hysterectomy, bilateral oophorectomy, number of chronic health disorders and 
time since menopause (in postmenopausal group). Furthermore, hypertension, hypercholesterolemia, diabetes and smoking history were fitted into the multivariate model to study the association of HRT use with the risk of CHD death. Age, parity, time since menopause and BMI were fitted as continuous variables in the model. Number of chronic health disorders (none, one, two, three or four to ten), hysterectomy (no, yes), bilateral oophorectomy (no, yes), hypertension (no, yes), hypercholesterolemia (no, yes), diabetes (no, yes) and smoking history (never, ever) were treated as categorical variables. Follow-up time was calculated as the time from 1 June 1994 to 14 May 2001 or date of death, which ever came first. $P$ values $<0.05$ were deemed significant.

\section{Results}

On 31 May 1994 the mean age of the 11667 women was 57.3 years (52.4-62.4 years) and the average time of follow-up was 6.7 years. Past or present HRT use was reported by $52.7 \%(n=6157)$ of the 11667 women (Table 1). The median duration of use of HRT in women who used it $\leq 5$ years was 2.2 years, and 8.7 years in women who used it $>5$ years (range 5.1-35 years). There were some marked differences between users and non-users of HRT (Table 1). Women who used HRT were significantly taller and thinner. They had also undergone more hysterectomies and bilateral oophorectomies compared with non-users of HRT. On the other hand, HRT users had more chronic health disorders than non-users. Women who had used HRT $>5$ years had fewer deliveries than non-users.

There were a total 361 deaths, including $58 \mathrm{CHD}$ and 29 breast cancer deaths during the 7 year followup (Table 2). Overall, 290 deaths were in the postmenopausal subgroup. During the observation time there were 46 deaths from $\mathrm{CHD}$ and 23 deaths from breast cancer in the postmenopausal subgroup. The total mortality is 4.51 per 1000 person-years in our entire study population $(n=11667)$. The all-cause mortality rate among the women of no HRT use is 5.37 per 1000 person-years, and in women who used HRT $\leq 5$ years 3.37 per 1000 person-years. All-cause mortality rate in women who used HRT $>5$ years is 4.16 per 1000 person-years (data not shown).

Use of HRT was not associated with mortality in the entire study population (Table 3 ) or in the postmenopausal subgroup (Table 4). In multivariate analyses of the entire cohort, the relative risk (RR) of CHD death was 0.79 (95\% confidence interval (CI) $0.36-1.73$ ) in women with HRT use $\leq 5$ years and 2.16 (95\% CI $0.93-4.98)$ in women with HRT use $>5$ years. Similarly, in the postmenopausal subgroup, HRT use was not associated with CHD mortality (Table 4). Breast cancer mortality tended to be associated with HRT use $>5$ years (hazard ratio $(\mathrm{HR})=2.62,95 \%$ CI $0.98-7.00)$ in the entire study population (Table 3). In the postmenopausal subgroup, breast cancer mortality was not associated with HRT use (for women who used HRT $>5$ years, $\mathrm{HR}=1.89,95 \%$ CI $0.65-$ 5.53) (Table 4).

Table 1 Baseline characteristics of the 11667 women according to HRT use history by 1994.

\begin{tabular}{|c|c|c|c|c|}
\hline \multirow[b]{2}{*}{ Characteristic } & \multicolumn{4}{|c|}{ Use of HRT by 1994} \\
\hline & $\begin{array}{c}\text { No use } \\
(n=5519)\end{array}$ & $\begin{array}{l}\leq 5 \text { years use } \\
(n=3945)\end{array}$ & $\begin{array}{l}>5 \text { years use } \\
(n=2203)\end{array}$ & $\begin{array}{c}\text { Total } \\
(n=11667)\end{array}$ \\
\hline Age, mean (S.D.) & $57.5(3.0)$ & $56.8(2.9)^{*}$ & $57.6(2.7)$ & $57.3(2.9)$ \\
\hline Height (cm, $n=11605$, mean (S.D.)) & $160.9(5.4)$ & $161.4(5.2)^{*}$ & $161.3(5.1)^{*}$ & $161.2(5.3)$ \\
\hline Weight (kg, $n=11123$, mean (s.D.) $)$ & $71.5(13.0)$ & $70.5(11.9)^{*}$ & $68.3(10.2)^{*}$ & $70.5(12.2)$ \\
\hline BMI $\left(\mathrm{kg} / \mathrm{m}^{2}, n=11066\right.$, mean (s.D.) & $22.2(3.9)$ & $21.8(3.5)^{*}$ & $21.1(3.0)^{\star}$ & $21.9(3.6)$ \\
\hline Parity $(n=11620$, mean (S.D.)) & $2.5(1.7)$ & $2.5(1.5)$ & $2.2(1.4)^{*}$ & $2.4(1.6)$ \\
\hline Time (years) since menopause (for postmenopausal), mean (S.D.) & $8.1(4.4)$ & $6.4(4.0)^{\star}$ & $9.3(3.8)^{*}$ & $7.7(4.3)$ \\
\hline Proportions of postmenopausal women, \% $(n)$ & $76.7(4233)$ & $83.0(3276) \dagger$ & $83.7(1845) \dagger$ & $80.2(9354)$ \\
\hline \multicolumn{5}{|l|}{ No. of chronic health disorders $(n=11667)$} \\
\hline None (\%) & 27.9 & $26.1 \dagger$ & $26.0 \dagger$ & 26.9 \\
\hline One $(\%)$ & 31.1 & $29.8 \dagger$ & $27.5 \dagger$ & 30.0 \\
\hline $2-3(\%)$ & 30.9 & $33.0 \dagger$ & $35.3 \dagger$ & 32.4 \\
\hline$\geq 4(\%)$ & 10.1 & $11.2 \dagger$ & $11.2 \dagger$ & 10.7 \\
\hline Bilateral oophorectomy, \% $(n=11585)$ & 3.9 & $9.7 \dagger$ & $19.5 \dagger$ & 8.8 \\
\hline Hypertension, \% (n=11667) & 18.3 & 17.4 & $15.5 \dagger$ & 17.5 \\
\hline Hypercholesterolemia, \% $(n=11667)$ & 15.2 & 16.1 & 16.7 & 15.8 \\
\hline Diabetes, \% $(n=11667)$ & 3.6 & $1.8 \dagger$ & $1.1 \dagger$ & 2.5 \\
\hline Smoking history, \% $(n=11363)$ & 18.6 & 20.2 & 17.9 & 19 \\
\hline
\end{tabular}

Comparison of each HRT group with group of no use of HRT by 1994 , ${ }^{\star} P<0.05$, ANOVA, $† P<0.05, \chi^{2}$-test. 
Table 2 Number of deaths for selected reasons in 11667 women.

\begin{tabular}{lrcrr}
\hline & \multicolumn{4}{c}{ Use of HRT by $\mathbf{1 9 9 4}$} \\
\cline { 2 - 5 } Deaths & No use & $\leq 5$ years & $>5$ years \\
$(n=5519)$ & $(n=3945)$ & $(n=2203)$ & $P$ \\
\hline All & 203 & $95 \dagger$ & 63 & 0.002 \\
CHD & 37 & $11 \dagger$ & 10 & 0.027 \\
Breast cancer & 15 & 6 & 8 & 0.251 \\
Colon cancer & 4 & 2 & 1 & 0.870 \\
Pulmonary embolus & 7 & 5 & 2 & 0.908 \\
Deep venous thrombosis & 3 & 1 & 1 & 0.796 \\
Stroke & 10 & 2 & 3 & 0.216 \\
\hline
\end{tabular}

Comparison of each HRT group with group of no use of HRT by 1994 in entire population $(n=11667), \uparrow P<0.05, \chi^{2}$-test.

\section{Discussion}

In the present prospective 7 year follow-up study, HRT did not affect overall or CHD mortality. On the other hand, HRT use $>5$ years tended to increase breast cancer mortality.

Our self-reported HRT-use data in 1996-1999 has been validated using a nationwide medical prescription register compiled by the Social Insurance Institution (KELA), Finland, where all delivered prescriptions are recorded. We found that postal inquiry is a reliable method to assess HRT use in postmenopausal women, although short-term HRT users often fail to report HRT use (L Sandini, unpublished observation).

Observational studies suggest that women who use hormones may be a self-selected group and may have healthier lifestyles with fewer risk factors than women who do not use hormones $(18-20)$. HRT users tend to be healthier, better educated, more physically active, leaner, and use alcohol more moderately than other women $(19,21)$. This finding has been referred to as the 'healthy user effect'. In this study, women who had used HRT were taller and thinner. Furthermore, they had undergone more hysterectomies and bilateral oophorectomies compared with nonusers of HRT. On the other hand, they reported more chronic health disorders than women who had not used HRT. Women who had used HRT $>5$ years also had fewer deliveries than non-users. Adjustment for these differences did not affect the results, however.

The total mortality rate is 4.51 per 1000 person-years in our entire study population $(n=11667)$. The total mortality rate in non-users of HRT is 5.37 per 1000 person-years and 4.16 per 1000 person-years among $>5$ year users. In 1995, the national total mortality rate for 55- to 59-year-old women was 4.4/1000 person-years and for 60- to 64-year-old women it was 6.73 per 1000 person-years (22). In 2000, the national total mortality rate for 55- to 59-year-old women was 4.1 per 1000 person-years and for 60- to 64-year-old women it was 6.45 per 1000 person-years (23).

CHD remains the leading cause of death in postmenopausal women around the world. It is well known that the incidence of CHD increases substantially after menopause, marking the end of the protective effect of endogenous estrogens against cardiovascular disease (24). That is why it is logical that a woman who stops HRT use will later lose the benefits of her HRT use.

Table 3 Relative risks of death from any cause, CHD and breast cancer in relation to HRT use history in 11667 women during the 7-year follow-up.

\begin{tabular}{|c|c|c|c|}
\hline & \multicolumn{3}{|c|}{ Use of HRT } \\
\hline & No $(n=5519)$ & Yes $(\leq 5$ years $(n=3945))$ & Yes $(>5$ years $(n=2203))$ \\
\hline All deaths $(n)$ & 203 & 95 & 63 \\
\hline Age adjusted & 1.0 & 0.97 & 1.04 \\
\hline $95 \% \mathrm{Cl}$ & - & $0.76-1.24$ & $0.78-1.39$ \\
\hline Multivariate & 1.0 & 1.05 & 1.06 \\
\hline $95 \% \mathrm{Cl}$ & - & $0.80-1.36$ & $0.78-1.46$ \\
\hline$P$ (multivariate) & 0.906 & 0.748 & 0.704 \\
\hline $\mathrm{CHD}(n)$ & 37 & 11 & 10 \\
\hline Age adjusted & 1.0 & 0.68 & 0.93 \\
\hline $95 \% \mathrm{Cl}$ & - & $0.34-1.34$ & $0.46-1.88$ \\
\hline Multivariate & 1.0 & 0.62 & 1.44 \\
\hline $95 \% \mathrm{Cl}$ & - & $0.29-1.31$ & $0.67-3.14$ \\
\hline Multivariate* & 1.0 & 0.79 & 2.16 \\
\hline $95 \% \mathrm{Cl}$ & - & $0.36-1.73$ & $0.93-4.98$ \\
\hline$P$ (multivariate $\left.{ }^{\star}\right)$ & 0.105 & 0.557 & 0.072 \\
\hline Breast cancer $(n)$ & 15 & 6 & 8 \\
\hline Age adjusted & 1.0 & 0.82 & 1.97 \\
\hline $95 \% \mathrm{Cl}$ & - & $0.32-2.13$ & $0.83-4.68$ \\
\hline Multivariate & 1.0 & 0.96 & 2.62 \\
\hline $95 \% \mathrm{Cl}$ & - & $0.32-2.82$ & $0.98-7.00$ \\
\hline$P$ (multivariate) & 0.124 & 0.935 & 0.055 \\
\hline
\end{tabular}

Multivariate covariates; age, BMI $\left(\mathrm{kg} / \mathrm{m}^{2}\right)$, parity, no. of chronic health disorders $(0,1,2$ or $3, \geq 4)$, hysterectomy $(\mathrm{y} / \mathrm{n})$ and bilateral oophorectomy $(\mathrm{y} / \mathrm{n})$. *Also adjusted for hypertension $(\mathrm{y} / \mathrm{n})$, hypercholesterolemia $(\mathrm{y} / \mathrm{n})$, diabetes $(\mathrm{y} / \mathrm{n})$ and smoking history (never/ever). 
Table 4 Relative risk of death from any cause, CHD and breast cancer in relation to HRT use history in 9111 postmenopausal women during the 7 year follow-up.

\begin{tabular}{|c|c|c|c|}
\hline & \multicolumn{3}{|c|}{ Use of HRT } \\
\hline & No $(n=4233)$ & Yes $(\leq 5$ years $(n=3276))$ & Yes $(>5$ years $(n=1845))$ \\
\hline All deaths & 156 & 78 & 56 \\
\hline Age adjusted & 1.0 & 0.99 & 1.11 \\
\hline $95 \% \mathrm{Cl}$ & - & $0.75-1.31$ & $0.81-1.51$ \\
\hline Multivariate & 1.0 & 1.07 & 0.99 \\
\hline $95 \% \mathrm{Cl}$ & - & $0.79-1.46$ & $0.71-1.39$ \\
\hline$P$ (multivariate) & 0.897 & 0.661 & 0.971 \\
\hline $\mathrm{CHD}(n)$ & 29 & 8 & 9 \\
\hline Age adjusted & 1.0 & 0.61 & 0.98 \\
\hline $95 \% \mathrm{Cl}$ & - & $0.28-1.36$ & $0.46-2.07$ \\
\hline Multivariate & 1.0 & 0.58 & 1.27 \\
\hline $95 \% \mathrm{Cl}$ & - & $0.24-1.43$ & $0.55-2.90$ \\
\hline Multivariate* & 1.0 & 0.84 & 1.97 \\
\hline $95 \% \mathrm{Cl}$ & - & $0.32-2.17$ & $0.80-4.86$ \\
\hline$P\left(\right.$ multivariate $\left.{ }^{\star}\right)$ & 0.231 & 0.710 & 0.142 \\
\hline Breast cancer $(n)$ & 12 & 5 & 6 \\
\hline Age adjusted & 1.0 & 0.91 & 1.62 \\
\hline $95 \% \mathrm{Cl}$ & - & $0.31-2.64$ & $0.61-4.33$ \\
\hline Multivariate & 1.0 & 0.94 & 1.89 \\
\hline $95 \% \mathrm{Cl}$ & - & $0.28-3.15$ & $0.65-5.53$ \\
\hline$P$ (multivariate) & 0.456 & 0.922 & 0.242 \\
\hline
\end{tabular}

Multivariate covariates; age, time since menopause, BMI $\left(\mathrm{kg} / \mathrm{m}^{2}\right)$, parity, no. of chronic health disorders $(0,1,2$ or $3, \geq 4)$, hysterectomy $(\mathrm{y} / \mathrm{n})$ and bilateral oophorectomy $(y / n)$. *Also adjusted for hypertension $(y / n)$, hypercholesterolemia $(y / n)$, diabetes $(y / n)$ and smoking history $($ never/ever).

This may partly explain the results of our study. Namely, any woman who reported any HRT/estrogen use (ranging from 0.05-35 years) was classified as an HRT user. An HRT user (either $\leq 5$ years or $>5$ years) could thus be a former user, current user, parttime user or continuous user, or a woman who had used HRT for some time and stopped and re-started use. An HRT user may have stopped use of HRT several years before the baseline of 31 May 1994. There is a possibility that these women who had stopped HRT use had lost the benefit of it, and that might be the reason why in our study the use of HRT was not associated with CHD death. We did not find any association between HRT and risk of death or risk of CHD death, although we carried out several analyses by using different HRT-use classifications (data not shown).

Sourander et al. reported in 1998 (13) their study where they examined 7944 women born between 1923 and 1930 who participated in a mammography screening for breast cancer, and who were followed up from 1987 to 1995 . The main findings in their study were that current estrogen replacement therapy was associated with the decreased cardiovascular mortality and sudden cardiac death. The RR for cardiovascular death among current users was only 0.21. There was no significant difference in the risk of breast cancer in their study.

Our main study does not distinguish between unopposed estrogen and combined therapy. In the Million Women Study (7) especially estrogen-progestagen combinations were associated with an increased risk of incident and fatal breast cancer. In that study, current users of HRT were 1.7-fold more likely than never-users to get breast cancer, and 1.2-fold more likely to die of breast cancer. The prospective cohort study in the Danish Nurses study found that HRT was not associated with a lower risk of death, ischemic heart disease or myocardial infarction (25). Their main finding was that HRT users with diabetes had an increased risk of death of all causes, ischemic heart disease and myocardial infarction. Their finding of no association between HRT and ischemic heart disease contrasts with most other observational studies, which have showed a protective effect of treatment on ischemic heart disease. They thought that one reason for their different results was that Danish nurses were not 'healthy users'. Finnish HRT users may be health-conscious, but HRT use is not limited only to healthy women. Like the Danish Nurses study (25), we did not find an HRT effect on overall or CHD mortality.

The WHI (1-5) trial of estrogen plus progestin vs placebo was stopped after a mean follow-up of 5.2 years by the Data and Safety Monitoring Board, because the test statistics for invasive breast cancer exceeded the stopping boundary for this adverse effect and the global index statistic supported risks exceeding benefits. In the WHI Trial (1) the risk of breast cancer (290 cases) was increased 1.3-fold and for stroke (212 cases) 1.4-fold. On the other hand the risk of colorectal cancer was decreased by $37 \%$. The mean age for the women in the WHI trial was 63 years compared with 57 years in our entire study population. In our study, women who had used HRT $>5$ years with a median duration of use of 8.7 years showed a 2- to 2.5-fold risk of breast cancer 
death compared with non-users of HRT. This risk tended to be significant in multivariate analysis. Apparently, the power of our study was not enough to show the association between breast cancer death (29 death cases) and HRT use. We carried out also a subanalysis on postmenopausal women with an intact uterus at baseline $(n=8213)$. Women with an intact uterus use combined HRT in Finland. In this multivariate analysis (adjustedage, BMI, parity, number of chronic health disorders, bilateral oophorectomy and time since menopause) RR of breast cancer death was 0.89 (95\% CI 0.27-3.01) in women with HRT use of ( $\leq 5$ years and $1.49(95 \%$ CI 0.44-5.04) in women with HRT use $>5$ years (data not shown). Use of combined HRT was not associated with breast cancer mortality in postmenopausal women who had an intact uterus. In their review of observational studies carried out by 2001, Bush et al. 2001 (14) take the view that the likelihood that HRT increases breast cancer death risk is small.

In the WHI trial $(1-5)$ women were randomized to receive conjugated equine estrogens combined with medroxyprogesterone acetate, whereas the Finnish women, like Danish nurses (23), with an intact uterus, mainly use estradiol combined with norethisterone acetate or levonorgesterel. Finnish women who have undergone a hysterectomy use mainly estradiol only. In our main analysis, HRT included both pure estradiol and estradiol combined with progesterone. Our postmenopausal subgroup data have been examined after exclusion of all women who had undergone hysterectomy ( $n=1141)$. In this multivariate analysis, use of combined HRT was not associated with risk of CHD death in postmenopausal women with an intact uterus ( $n=8213)$, even though hypertension, diabetes mellitus, hypercholesterolemia and smoking history were adjusted in multivariate analysis $(\leq 5$ years users vs non-users: $\mathrm{RR}=0.94,95 \%$ CI $0.36-2.47$ and $>5$ years users vs non-users: $\mathrm{RR}=2.63,95 \% \mathrm{CI}$ 0.95-7.29). The WHI showed a significantly increased risk of non-fatal $\mathrm{CHD}$ associated with combined HRT $(1,5)$. In contrast to the WHI study, HRT did not significantly affect the risk of CHD death in our study.

In conclusion, our findings suggest that a history of HRT use may not be associated with overall mortality or CHD mortality in 52- to 70-year-old women. Longterm HRT use, $>5$ years, may increase breast cancer mortality in these women.

\section{Acknowledgements}

The authors would like to thank Kuopio University Hospital, National Statistics Finland and Academy of Finland (grant No. 203403) for support of this work.

\section{References}

1 Writing Group for the Women's Health Initiative Investigators, Risks and benefits of estrogen plus progestin in healthy postmenopausal women: principal results From the Women's Health Initiative randomized controlled trial. Journal of the American Medical Association 2002288 321-333.

2 Shumaker SA, Legault C, Rapp SR, Thal L, Wallace RB, Ockene JK, Hendrix SL, Jones BN III, Assaf AR, Jackson RD, Kotchen JM, Wassertheil-Smoller S, Wactawski-Wend J, for the WHIMS Investigators, Estrogen plus progestin and the incidence of dementia and mild cognitive impairment in postmenopausal women: the Women's Health Initiative Memory Study: a randomized controlled trial. Journal of the American Medical Association 2003 $2892651-2662$.

3 Rapp SR, Espeland MA, Shumaker SA, Henderson VW, Brunner RL, Manson JE, Gass ML, Stefanick ML, Lane DS, Hays J, Johnson KC, Coker LH, Dailey M, Bowen D, for the WHIMS Investigators, Effect of estrogen plus progestin on global cognitive function in postmenopausal women: the Women's Initiative Memory Study: a randomized controlled trial. Journal of the American Medical Association $20032892663-2672$.

4 Wassertheil-Smoller S, Hendrix SL, Limacher M, Heiss G, Kooperberg C, Baird A, Kotchen T, Curb JD, Black H, Rossouw JE, Aragaki A, Safford M, Stein E, Laowattana S Mysiw WJ, for the WHI Investigators, Effect of estrogen plus progestin on stroke in postmenopausal women: the Women's Health Initiative: a randomized trial. Journal of the American Medical Association $20032892673-2684$.

5 Manson JE, Hsia J, Johnson KC, Rossouw JE, Assaf AR, Lasser NL, Trevisan M, Black HR, Heckbert SR, Detrano R, Strickland OL, Wong ND, Crouse JR, Stein E Cuchman M, for the WHI Investigators, Estrogen plus progestin and the risk of coronary heart disease. New England Journal of Medicine $2003 \mathbf{3 4 9}$ $523-534$.

6 Hulley S, Grady D, Bush T, Furberg C, Herrington D, Riggs B \& Vittinghoff E. Randomized trial of estrogen plus progestin for secondary prevention of coronary heart disease in postmenopausal women. Heart and Estrogen/Progestin Replacement Study (HERS) Research Group. Journal of the American Medical Association $1998280605-613$.

7 Million Women Study Collaborators, Breast cancer and hormonereplacement therapy in the Million Women Study. Lancet 2003 $362419-427$.

8 Grodstein F, Stampfer MJ, Colditz GA, Willett WC, Manson JE, Joffe M, Rosner B, Funchs C, Hankinson SE, Hunter DJ, Hennekens CH \& Speizer FE. Postmenopausal hormone therapy and mortality. New England Journal of Medicine 1997336 1769-1775.

9 Barrett-Connor E. Hormone replacement therapy. British Medical Journal $1998317457-461$.

10 Grady D, Rubin SM, Petitti DB, Fox CS, Black D, Ettinger B, Ernster VL \& Cummings SR. Hormone therapy to prevent disease and prolong life in postmenopausal women. Annals of Internal Medicine 1992117 1016-1037.

11 Lauritzen C. Clinical use of estrogens and progestogens. Maturitas 199012 199-214.

12 Komulainen MH, Kröger H, Tuppurainen MT, Heikkinen AM, Alhava E, Honkanen R \& Saarikoski S. HRT and vitamin D in prevention of non-vertebral fractures in postmenopausal women; a 5 year randomized trial. Maturitas 199831 45-54.

13 Sourander L, Rajala T, Raiha I, Makinen J, Erkkola R \& Helenius H. Cardiovascular and cancer morbidity and mortality and sudden cardiac death in postmenopausal women on estrogen replacement therapy (ERT). Lancet $1998 \mathbf{3 5 2}$ 1965-1969.

14 Bush TL, Whiteman M \& Flaws JA. Hormone replacement therapy and breast cancer: a qualitative review. Obstetrics and Gynecology $200198498-508$.

15 Barrett-Connor E \& Grady D. Hormone replacement therapy, heart disease, and other considerations. Annual Review of Public Health $19981955-72$.

16 Causes of Death. Helsinki: Statistics Finland, 2002. (www.statfin.stat.fi/statweb/health/causes of death 1969-2003). 
17 Lahti RA \& Penttila A. The validity of death certificates: routine validation of death certification and its effects on mortality statistics. Forensic Science International 2001115 15-32.

18 Posthuma WF, Westendorp RG \& Vandenbroucke JP. Cardioprotective effect of hormone replacement therapy in postmenopausal women: is the evidence biased? British Medical Journal 1994 398 1268-1269.

19 Matthews KA, Kuller LH, Wing RR, Meilahn EN \& Plantinga P. Prior to use of estrogen replacement therapy, are users healthier than nonusers? American Journal of Epidemiology $1996 \mathbf{1 4 3}$ 971-978.

20 Hormone replacement therapy, Clinical Synthesis Panel on HRT. Lancet $1999354152-155$.

21 Rodriquez C, Calle EE, Patel AV, Tatham LM, Jacobs EJ \& Thun MJ. Effect of body mass on the association between estrogen replacement therapy and mortality among elderly US women. American Journal of Epidemiology 2001153 145-152.

22 Causes of Death. Helsinki: Statistics Finland, 1995.

23 Causes of Death. Helsinki: Statistics Finland, 2000.

24 Tuppurainen M \& Saarikoski S. Estrogens and ageing. Advances in Neurology 200391 101-106.

25 Løkkegaard E, Pedersen AT, Heitmann BL, Jovanovich Z, Keiding N, Hundrup YA, Obel EB \& Ottesen B. Relation between hormone replacement therapy and ischaemic heart disease in women; prospective observational study. British Medical Journal $2003326426-431$.

Received 28 June 2005

Accepted 26 September 2005 